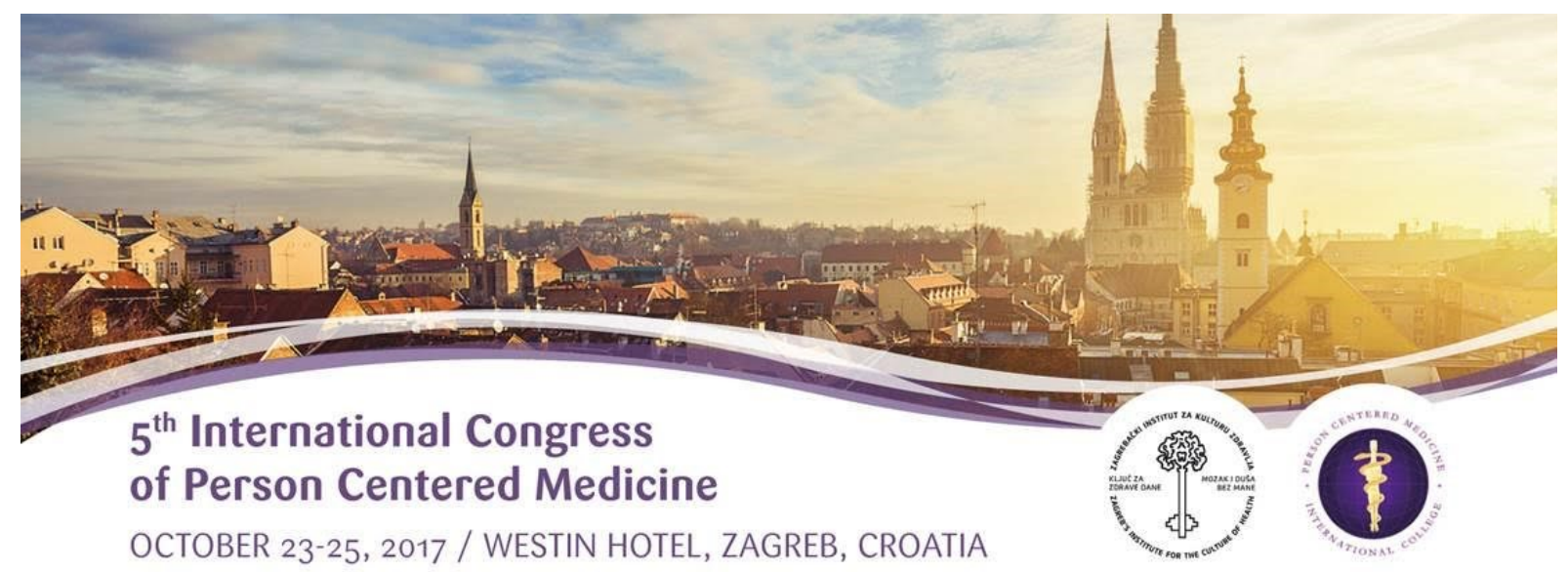

\title{
INVITATION LETTER
}

\section{Dear Colleagues and Friends,}

It gives us great pleasure to invite you to participate in the 5th International Congress of Person Centered Medicine in October 2017 in Zagreb. The International Collegeof Person Centered Medicine emerged from the ongoing annual Geneva Conferences and the aspiration to promote a medicine of the person, for the person, by the person and with the person. The main theme of our upcoming 5th International Congress in Zagreb will be Cancer and Person Centered Medicine and Health.

This theme will unfold through lectures, symposia, workshops, oral and poster presentations and a range of timely topics from medical training to stakeholders in health education; clinical topics such as primary care, mental health, pediatrics, geriatrics as well as care for major chronic diseases (including circulatory, respiratory, cancer and diabetes), pain management and palliative medicine; and public health topics such as services and policies for prevention and health promotion.

Selecting Zagreb as congress site was in no small measure connected to the enduring legacy of Professor Andrija Stampar, president of the first WHO World Health Asembly (which coined the ongoing definiton of health), founder of Zagreb University's school of public health, and pioneer of person- and people-centered care. Zagreb with its beautiful fin-de-siècle European architecture will offer an inspirational and friendly atmosphere for our discussions and plenty of opportunities for leisurely and stimulating explorations. Zagreb will be waiting with its thousand fascinating faces to make us feel at home, ready to renew old friendships and develop new ones.

We are looking forward to greeeting you personally at our Fifth International Congress in Zagreb!

Cordially yours,

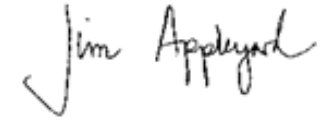

Professor James Appleyard President, International College of Person-centered Medicine President of the Congress

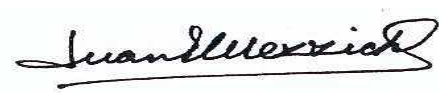

Professor Juan Mezzich Secretary General, International College of Person Centered Medicine Chair, CongressOrganizingCommittee

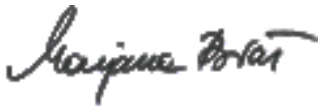

Professor Marijana Bras, Co-Chair,Congress Organizing Committee

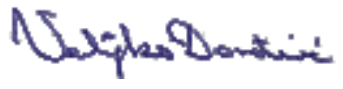

Professor Veljko Djordjevic Chair, Congress Scientific Committee 